\title{
Lorenzo Luzuriaga: una biografía truncada (1889-1959)
}

\section{La ruptura de la guerra civil y el exilio (1936-1959)}

1936 será ya siempre, para los pueblos de España, la raya de demarcación que trunca irreversiblemente la vida de sus gentes en el siglo XX. Ya nada volverá a ser igual para casi nadie. En realidad, el punto de inflexión verdadero había tenido lugar el 14 de abril de 1931, pero la sublevación militar del 36 y la liquidación criminal de la experiencia republicana en los años siguientes, graban a sangre y fuego esa fecha -1936 - en la conciencia traumatizada de la mayoría de los españoles.

Nuestro personaje, el pedagogo Lorenzo Luzuriaga Medina, un manchego de Valdepeñas, nacido en 1889 y con sangre vasconavarra y castellana en sus venas, fue también uno de aquellos españoles "del éxodo y del llanto" que abandonaron el país en aquel otoño para muchos "apocalíptico" de 1936 en Madrid, como consecuencia de los virulentos combates desatados en las afueras de la capital, ya en plena guerra civil.

Luzuriaga es, pues, para la historia, uno más de la larga lista de exiliados que dejan España, entre la incertidumbre y la desolación, poco tiempo después de iniciarse la contienda. En 1936 comenzará ya para él, el siempre duro exilio, aunque algunos hayan podido hablar, en ciertos casos y con no poca ironía, del "dorado exilio"...

José Luis Abellán, en su obra La cultura en España, habla de una emigración en masa de profesores, pensadores, escritores y artistas. Entre ellos, Américo Castro, Rafael Alberti, Rafael Altamira, León Felipe, Luis Cernuda, Arturo Barea, Max Aub, Juan Marichal, Lorenzo Luzuriaga, José Castillejo, Joaquín Xirau, Arturo Duperier, Emilio Mira y López, María Zambrano, Wenceslao Roces, etc. etc.

Sobre tan alto número de intelectuales cayó, durante los años del franquismo, en España, una espesa niebla de silencio, calumnias y rencores. Todos ellos desaparecieron, hasta tiempos muy recientes, de los escaparates de la cultura. Para los que aquí quedaron, para el pueblo español en general, era como si efectivamente hubieran muerto. 0 peor aún, como si nunca hubieran existido.

Ingente es la cantidad de estudios realizados sobre esta gran odisea contemporánea. Grande fue la solidaridad que despertó en el mundo. Y será también, sin duda alguna, fuente de inspiración de primera mano para gran número de escritores y artistas. Y si el exilio era para ellos lo más parecido a la nada, España será para muchos un infierno... El apogeo del fascismo en Alemania e Italia coincide con el final de la guerra civil. Ese mismo año, las tropas hitlerianas inician la invasión de Europa y el exterminio de pueblos enteros. 
Será la guerra más feroz. Será la IIª guerra mundial... En España seguiría desencadenándose una fortísima represión.

Así pues, 1939 será para muchos un punto sin retorno. Nada podrá seguir siendo igual para ellos. Porque otra —o incluso muy otra - será la realidad del extranjero, por muy próxima que la sintamos a nuestra propia cultura. Otros son los problemas en tierras extrañas, otras las inquietudes y muy distintas las razones de la actuación personal de cada uno.

Por eso, Luzuriaga, que ya dejaba una obra cuajada en España, tendrá sus dudas y vacilaciones en el exilio. Difícilmente podía haber una línea de continuidad investigadora -sobre todo en el ámbito de las ciencias sociales, tan en el corazón de nuestra propia vida- después de haber vivido unos acontecimientos tan duros. Una derrota como aquella transforma cualquier proyecto personal de vida — como diría Ortega-. Por esa razón, la producción pedagógica de Luzuriaga en el exilio continúa, aparentemente, en idéntica progresión que en España —o incluso se acelera—, pero será en realidad una producción sustancialmente distinta. Le faltará el contacto con la realidad práctica conocida y propia. Le faltarán los nutrientes naturales. Le faltará alma. Le faltará vida.

La guerra civil de 1936-1939 seguía tercamente presente... Como un puñal, como una daga. 1936 era, efectivamente, un punto sin retorno. Tan es así que Luzuriaga, en el exilio, tardará un poco en volver, por ejemplo, sobre los temas históricos. Y tarda un poco en reflexionar en voz alta sobre España. Pero lo hará un día. Y lo hará con hondura -aunque algo se haya desgarrado para siempre- En cambio, su maestro y amigo Ortega y Gasset, que lo había prometido reiteradamente, no lo hará nunca. El silencio será su juicio sobre el gran drama bélico de la España contemporánea.

Quien sí lo hará -y muy pronto— será su admirado amigo José Castillejo, que escribe, en el exilio, nada menos que una síntesis de la historia de la educación en España, con este título, no se sabe si provocador, retador, indignado o conclusivo: War of ideas in Spain, que publica primero en inglés y en Londres. Más tarde, años después de su muerte, en 1976, aparecerá la versión española en las Publicaciones de la Revista de Occidente, con ese mismo título: Guerra de ideas en España. Los institucionistas querían dejar oír su voz. Y lo hacían, como se ve, con energía. En cierta carta dirigida a Castillejo, Luzuriaga le mostrará su reconocimiento y su emoción cuando le cuente sus sentimientos al oír su voz en la distancia (se refiere a las famosas charlas de José Castillejo en la BBC de Londres, en los años de la II Martínez Nadal, en la editorial Casariego-). En relación con José Castillejo, el otro gran manchego, no debería dejar de leerse el hermoso libro escrito por su mujer, Irene Claremont, en inglés, y primorosamente traducido por Jacinta Castillejo, su hija, al español, en Cátedra, con este título: Respaldada por el viento.

Cuando Luzuriaga publique, en Buenos Aires (a donde llegaría después de breves estancias en Londres, Glasgow y Tucumán), su célebre Antología pedagógica, su Historia de la Educación y de la Pedagogía y su Historia de la Educación pública, entre otras obras 
conocidas, tendrá ya la sensación de que su obra en España quedaba muy atrás. Y empezará entonces a tomar conciencia de que, probablemente, podría ser ya para siempre un exiliado...

Como muy bien dice Adolfo Sánchez Vázquez —y afirma también y reafirma desde el hálito poético más puro Emilio Prados- (dos malagueños inexorablemente prendidos por el amor de su tierra), a partir de un determinado momento, el hecho de ser exiliado deja de ser tal y se convierte en un estado. Llegados a este punto, empezarán a tener la certeza de que, en cualquier parte, en España o en América, ellos, los hombres y mujeres de la España peregrina serán ya para siempre extraños — se sentirán extrañados- en una u otra orilla del Atlántico... Y esa especie de tristeza inmensa o de nostalgia infinita que tal estado conllevaba, esa especie de saudade da saudade - como dice en uno de sus fados María Teresa de Noronha-, creo yo que ha impregnado la obra de todos ellos en América. Y, por supuesto, también la obra de Lorenzo Luzuriaga...

\section{Años de formación de Lorenzo Luzuriaga (1904-1914)}

Lorenzo Luzuriaga Medina había nacido en Valdepeñas (Ciudad Real) el 29 de octubre de 1889. Era hijo de un maestro de Murrieta (Navarra), Santiago Luzuriaga, y de Ángeles Medina, de Socuéllamos. En una nota autobiográfica él mismo rememora sus orígenes y habla de su padre como director de una escuela en Valdepeñas, y de su madre, hermana de un maestro de la misma escuela. Y añade: "Tanto mi padre como mi madre se casaron en segundas nupcias, teniendo mi padre un hijo, Fermín, y mi madre otro, Recaredo, que ya eran maestros. Así pues, he tenido padre maestro, dos tíos maestros y dos hermanos maestros; no se puede pedir más pedagogía...".

Decía esto Luzuriaga en un boletín de la editorial Losada, Negro sobre Blanco, en el que, en 1961, se glosaba su vida, sólo dos años después de su muerte. Era el primer homenaje de la editorial a su responsable máximo en publicaciones pedagógicas. Su hijo mayor, Jorge Luzuriaga Navarro, recientemente fallecido en Buenos Aires, nos decía en una carta de 29 de octubre de 1978: "Cuando nació mi padre, el suyo tenía ya 60 años y su madre alrededor de 40. De ahí que al casarse mis abuelos, tuviese ya cada uno un hijo maestro...".

Y en la misma carta, Jorge Luzuriaga aclaraba: "Mi abuelo terminó su carrera como director del importante grupo escolar bilbaíno llamado o conocido - no estoy seguro de que éste fuera su nombre oficial- Escuelas de Alvia". Como vemos, el padre de D. Lorenzo se traslada pues a Bilbao y allí muere al poco tiempo. El pequeño Lorenzo —o Narciso Eladio Lorenzo, tal y como reza su partida de nacimiento - se va con su madre a Aravaca (Madrid) al amparo de uno de sus hermanos mayores - Recaredo-. Y con la ayuda económica de éste estudia Magisterio en la Escuela Normal Central de Madrid. El período escolar primario lo había pasado en Valdepeñas y Aravaca. Sus estudios normalistas los realiza entre 1904 y 1908. 
El año 1909 ingresa en la Escuela Superior del Magisterio, después de conseguir una beca que había solicitado por falta de recursos económicos. En esa época, y mientras preparaba su ingreso en la Escuela Superior, acude a la biblioteca del Museo Pedagógico Nacional. "Allí acudía — dice en sus notas autobiográficas inéditas— para mis lecturas, que eran muchas". Y allí conoció a Manuel Bartolomé Cossío, que le presentó a Giner. "Este fue - dice- el encuentro decisivo de mi vida". D. Francisco le hizo entrar en la Institución Libre de Enseñanza, en la que fue a la vez alumno y maestro desde 1908 a 1912.

Jorge Luzuriaga, en la carta citada, nos dice: "Cuando Cossío le presentó a D. Francisco mi padre le pidió una beca para ir a Alemania. D. Francisco ante su extremada juventud -tenía entonces 17 años- le ofreció en cambio que se quedase en la ILE como maestro y alumno a la vez". Durante estos años, Luzuriaga fue profesor de las colonias escolares de vacaciones organizadas por el Museo Pedagógico Nacional. En 1908 va como lector de español a la Normal de Montpellier. Y en 1909 recibe una pensión para estudiar en Alemania durante 10 meses.

Los años 1908 y 1909 suponen, por tanto, para Luzuriaga el primer contacto con la ILE y con la Escuela Superior de Estudios del Magisterio. Es decir, con las instituciones -y personas- que van a determinar la trayectoria intelectual de toda su vida. Si en la ILE estaban Giner y Cossío, en la Escuela se encontrará con Ortega, que acababa de llegar de Marburgo. Y junto a ellos, repartidos en ambas instituciones, Simarro, A. Buylla, Luis de Zulueta, etc. Se acercan para Luzuriaga años de formación que serán decisivos en su vida. A estos encuentros habrá que añadir otros que, en conjunción, irán trazando el perfil intelectual, la ideología política, la formación científica y el talante humano del joven Luzuriaga.

Como decíamos, tras su entrada en la ILE, en 1909 hace el ingreso en la Escuela Superior del Magisterio. En el curso 1909-10 se presentan 74 varones y 110 mujeres. Irá aprobando curso a curso sin problemas y se licenciará en1912 con el número 4 de su promoción. En ese mismo año es nombrado ya Inspector de Primera Enseñanza de la zona de Xinzo de Limia (Ourense) y se casa con María Luisa Navarro, a quien había conocido en la Escuela. Este matrimonio fortalecerá la línea intelectual e ideológica futura de Luzuriaga. Cambiará su destino y le dará otro "tono" social a su vida. En sus notas autobiográficas dice, hablando de la Escuela: "Y lo que es más importante, allí conozco a Maruja, con quien me caso apenas terminamos nuestros estudios en 1912".

María Luisa Navarro pertenecía a una familia aristocrática de Cádiz, con numerosos marinos de guerra entre sus antepasados. A pesar de su origen aristocrático, el padre de María Luisa fue un apasionado republicano y tuvo que permanecer varios años en el exilio. Allí nació María Luisa, en Sète (Francia). En la carta citada, Jorge Luzuriaga decía: "Mi madre, pues, nació y murió en el destierro político. ¡Qué historia la de la España contemporánea!"... Efectivamente, María Luisa Navarro moriría en Buenos Aires en 1947. (Todos los datos referidos a la esposa de Lorenzo Luzuriaga podrán verse muy pronto en la tesis doctoral que sobre ella está realizando Dolores Cotelo Guerra y en la que se ponen de relieve los numerosos aspectos en los que fue un personaje clave de la familia, además de 
una destacada profesora del Colegio Nacional de Sordomudos y mujer de una vida social muy intensa dentro de una cierta tradición cultural republicana).

Después de su destino como Inspector en Xinzo de Limia, Luzuriaga es nombrado para el mismo cargo en Guadalajara. Y como resultado de su primera, aunque corta estancia en Alemania, publicará Direcciones actuales de la Pedagogía en Alemania, su primer libro. 1913 será un año singularmente prolífico para el "curriculum" de Lorenzo Luzuriaga. En él, además de la intensa actividad del momento, recoge los frutos primeros del trabajo realizado entre 1908 y 1912. Y puede materializar así toda una serie de proyectos profesionales: primeras traducciones del alemán, artículos en el Boletín de la Institución Libre de Enseñanza -y en otras revistas, como La Inspección de Primera Enseñanza-, así como un cierto número de estudios preliminares en varias obras clásicas de la historia de la educación.

Durante el curso 1913-14 estudia en Jena y Berlín con los profesores Münch y Rein. Hasta allí se desplaza con su mujer y su primer hijo, Jorge. Al finalizar el curso, regresa a España y comienza su etapa de funcionario, profesor y publicista, que sólo interrumpirá esporádicamente con sus visitas al extranjero para dar conferencias, asistir a congresos o realizar esa puesta al día cultural y científica que será una característica común a todos los hombres de la generación del 14. 1914 es el año —el de su generación, que él mismo bautizó- en el que comienza la tarea densa, continuada y estable de creación intelectual. Como se ve, muy en la línea de lo que pretendía, por ejemplo, José Castillejo, al frente de la Junta de Ampliación de Estudios e Investigaciones Científicas: ir a Europa, aprender, regresar y ponerse manos a lo obra...

Si recapitulamos un poco estos veinte y tantos años de la vida de Lorenzo Luzuriaga, que de alguna manera marcan su destino, pensamos que, sin duda, el ambiente familiar - tan "cargado de pedagogía", como él mismo dice con cierta ironía- ha debido de pesar lo suyo en ese proyecto personal de vida que es la vocación. Respira los problemas de la enseñanza desde niño. Todos los problemas. Y lo hace en un lugar manchego, Valdepeñas, donde su madre hunde sus raíces ancestrales.

El primer escenario del niño Narciso Eladio Lorenzo será la Castilla austera y cervantina que redescubriría más tarde en las preocupaciones de los hombres del 98. Preocupaciones que iban a culminar en la mitificación de esa tierra y de su pasada grandeur. Preocupaciones, en definitiva, que obnubilarían muchas conciencias a la hora de intentar la reorganización de un Estado en ruinas.

Ese enraizamiento de Luzuriaga en Castilla se intensificará más tarde cuando se traslade a Aravaca, cerca de Madrid. Y de Madrid ya sólo se moverá esporádicamente. Sus raíces humanas no pueden ser por tanto más castellanas. Podremos comprobarlo más tarde, cuando pida su primer destino como inspector. Obsérvese el orden de preferencia: Madrid, Toledo, Guadalajara, Avila, Segovia... Madrid será pronto su destino definitivo. No volverá a Valdepeñas, "donde ya no nos quedaban sino parientes muy lejanos", como él mismo dice. 
Vocación de maestro, estirpe castellana, hombre de ciudad: he aquí las primeras características humanas que se pueden observar en nuestro autor. De ellas derivarán, entre otras, sus preocupaciones permanentes por todo lo relacionado con la educación y la enseñanza; su estilo austero, sobrio; su sequedad en el trato, su cosmopolitismo -a un tiempo-y el deseo de hallarse siempre cerca de los centros de decisión y de poder.

El joven Luzuriaga debía ir todos los días a clase, desde Aravaca a Madrid, a pie. Lo hacía en zapatillas, para no gastar los zapatos - nos cuenta-. Sabemos así de su pobreza de medios... Junto a la vocación por la enseñanza, vivió muy de cerca la estrechez económica y la precariedad que eran comunes al magisterio de entonces. Por eso, más tarde, cuando en sus artículos de EI Sol hable de los desposeídos, no dudará en incluir entre ellos a los maestros -los "rebeldes del magisterio", como él les llama-. De ahí deben provenir buena parte de sus inclinaciones socialistas y el radicalismo de su juventud. Un pequeño burgués con dificultades suele ser un rebelde radicalizado. Todo eso se verá muy claro en las posiciones políticas que va a adoptar a partir de 1914... (Muy lejos por cierto de la "inocencia liberal" de la guerra civil y de la posguerra a las que se refiere sin demasiado fundamento Christopher $\mathrm{H}$. Cobb en su artículo de la revista Historia Contemporánea, 17, "Lorenzo Luzuriaga: el camino del exilio, de Glasgow a Tucumán. La desilusión de un liberal "[1998]).

Y no se olvide que el ambiente con que primero conecta Luzuriaga es precisamente el de la Institución. No elige en principio lo "oficial" o lo "práctico"; elige la renovación y la vanguardia. Elige el ambiente reformador, regeneracionista, contestatario. Todo un síntoma... Y encuentra allí esa atmósfera intelectual que buscaba, lejos del conformismo y de la rutina. De "institución difusa" califica María Dolores Gómez Molleda a la ILE. Ascetismo y rigor moral. Austeridad muy a tono con los más íntimos deseos de renovación moral, social y política.

Con Giner, descubre Luzuriaga una nueva concepción de la educación y de la pedagogía. Y descubre también el papel de los grandes educadores en la formación de cuadros. Aprende de Giner la tolerancia y la concordia como método de convivencia para fomentar el espíritu creativo, virtudes que también encuentra en un Cossío o en un Castillejo. Luzuriaga se empapa de esa atmósfera educativa activa, por un lado, difusa en ocasiones, pero, en todo caso, permanente, de la Institución y de su animador principal. Da clases a los pequeños de la Institución y contempla en vivo la acción pedagógica cotidiana de Giner.

Allí aprenderá Luzuriaga el principio práctico del activismo pedagógico, sobre el que luego teorizaría. Como recordará más tarde, en su libro La Institución Libre de Enseñanza y la educación en España (1957) —auténtico testamento pedagógico del educador de Valdepeñas-, la ILE "se adelanta a las ideas de la educación nueva".

A partir de 1915 —después de la muerte de Giner- Luzuriaga trabajará regularmente con Cossío, sin duda la gran autoridad pedagógica en España durante el primer tercio del siglo XX. Y lo hará con idéntica devoción. Así pues, Giner y Cossío son las dos primeras influencias armónicas, poderosas y determinantes en el joven Luzuriaga. Si de Giner he- 
reda la tolerancia, el espíritu crítico, el rigor científico, el amor por la obra de la educación, de Cossío heredará un modelo para esa acción pedagógica concreta. Modelo a cuyo lado se forma durante varios años decisivos. Y si Giner es para él el precursor de lo que será más tarde la educación nueva, Cossío será el inspirador del proceso de renovación interna conocido como escuela activa y el animador del proceso de renovación externa de la escuela unificada (concepto este último importado del alemán Einheitschule por el propio Luzuriaga).

A estas influencias y a estas inquietudes, se suma, en 1909, el primer encuentro de Luzuriaga con Ortega. Las clases de Ortega en la Escuela de Estudios Superiores del Magisterio son las que descubren a Luzuriaga el mundo de la filosofía. A partir de ese momento, la influencia de Ortega en Luzuriaga será constante, aunque también será coyuntural, intermitente. La atracción que Ortega ejercía sobre Luzuriaga era una atracción de brillo intelectual, de prestigio, de cultura sofisticada. Pero el instinto político y la posición de clase de Luzuriaga sigue, en aquellos años, otros derroteros. Su relación mutua, ya en un plano de mayor igualdad, se va a intensificar, sobre todo, a partir de 1914. Es entonces cuando va a aparecer el Ortega teórico de la educación y especialmente preocupado por los problemas pedagógicos. Y junto a él, el Luzuriaga más comprometido y radical.

\section{Evolución ideológica y política (1914-1931)}

A su regreso de Alemania, Luzuriaga se reinstala definitivamente en Madrid. "Manos a la obra" es una especie de consigna de la generación del 14 para ponerse inmediatamente a la acción. Todos tratan de "hacer precisión" en sus quehaceres científicos, en su profesión, pero todos tendrán que simultanearlos con la dedicación política, tal y como exigía Ortega -y tal y como nos recuerda Juan Marichal en su obra La vocación de Manuel Azaña-. Está lanzada entonces la Liga de Educación política. Se está gestando España. Semanario de la vida nacional, auténtica plataforma de los "nietos de Giner", que pronto serían gestores de la magna experiencia republicana de 1931-1936. Se inicia pues la renovación política y se abre también una época de renovación pedagógica. Entramos en una nueva etapa de lucha por el cambio social.

Luzuriaga sabía muy bien que la educación -o determinada concepción de los fines educativos- está siempre en función de un determinado proyecto político. Porque, ¿dónde deben separarse - si es que deben- educación, cultura y política? Luzuriaga se planteará este problema, reiterada y contradictoriamente, a lo largo de su obra en España y en el exilio. Tratará de salvaguardar su libertad individual, su independencia y la independencia de sus obras de creación (defenderá siempre encarnizadamente su Revista de Pedagogía, que aparecerá ininterrumpidamente entre 1922 y 1936), aunque no por eso va a renunciar a la lucha por unos ideales claros de progreso, que le van a llevar desde las posiciones socialistas más radicales a un republicanismo también muy militante, aunque de más amplio espectro... Luzuriaga va a pasar del radicalismo de la época de sus colaboraciones en el semanario España (1915-16) y el diario El Sol (1917-21) a la prudencia 
política de los primeros tiempos de la Revista de Pedagogía, y del radicalismo republicano al desconcierto del exilio y de la "guerra fría".

La lectura ideológica y política de sus escritos de entonces nos ofrece la imagen de un Luzuriaga muy dentro de las posiciones socialistas más avanzadas, elaborando ya los primeros elementos de la escuela única - concepto con el que sustituye el de escuela unificada, sin duda por la influencia de París-, divulgando cuestiones básicas de organización escolar, presentando en España a autores, teorías y movimientos pedagógicos de vanguardia, etc. En suma, Luzuriaga es un claro ejemplo de las estrechas relaciones históricas existentes entonces entre la "fundación" de Giner de los Ríos y la "fundación" de Pablo Iglesias.

Se configuran así las tres influencias principales en el joven Luzuriaga: institucionismo, orteguismo y socialismo. Las tres, en distinta proporción y en momentos también distintos y siempre en función de la coyuntura sociopolítica española. Convendría señalar, no obstante, que sus preocupaciones políticas terminarían cediendo ante las profesionales. El pedagogo de Valdepeñas sabía que la política tenía un peso decisivo en su profesión, pero su dedicación principal seguiría siendo una dedicación pedagógica y técnica.

Publica Luzuriaga en estos años decisivos obras tan significativas como Documentos para la historia escolar de España, materiales indispensables para la reconstrucción de la escuela en España; La preparación de los maestros, un manual para los normalistas; El analfabetismo en España, un estudio sobre nuestra realidad socioeducativa de entonces; o la serie, inscrita en el movimiento internacional de renovación pedagógica de la Escuela Nueva, La escuela unificada, Las escuelas nuevas y Escuelas de ensayo y reforma. Y redacta igualmente las Bases para un programa de instrucción pública, que presenta en un Congreso del PSOE (1918).

\section{Militancia republicana y reconocimiento internacional (1931-1959)}

En 1931, cuando se proclama la República, Luzuriaga es un hombre política y profesionalmente ya muy instalado. No obstante, su militancia republicana será sumamente entusiasta desde el primer momento. Y lo será en todas las vicisitudes de la República, con el Bienio Negro, el Frente Popular o la guerra civil. Luzuriaga era un republicano de la cabeza a los pies.

Ya en 1930 -año de transición, en casi todos los aspectos-, el pedagogo manchego es, por ejemplo, un destacado miembro del movimiento internacional de la Escuela Nueva. Y su revista, la Revista de Pedagogía, que él había fundado, en unión de su mujer, María Luisa Navarro, y que dirigió siempre, desde 1922 hasta el mismo julio de 1936 -estamos hablando de una revista que ejerció una notable influencia en la vanguardia educativa española de los años 20 y 30-, era portavoz de ese movimiento en el que militaba lo mejor de la pedagogía internacional, desde A. Ferrière hasta el propio Luzuriaga. Luzuriaga era nombrado entonces Delegado del Gobierno en la Oficina Internacional de Educación de 
Ginebra, presidía la Liga española de Educación Nueva, asistía a varios Congresos internacionales relacionados con la educación, etc.

En 1931 será nombrado miembro del Consejo Nacional de Cultura. Colabora en Crisol, donde publicará un artículo célebre: Al servicio de la República: llamada al Magisterio, en el que dirá, entre otras cosas: "Estamos ante un proceso profundo. No basta con la simple adhesión... Hay que educar republicanamente... Los maestros serán ejes principales de nuestra República...". En mayo de ese mismo año, aparecerá otro artículo del propio Luzuriaga titulado La República Española; se trata de un análisis político y una glosa sobre la proclamación republicana. Y en el número de septiembre de su revista, publicará las Bases para un Anteproyecto de Ley de Instrucción Pública inspiradas en la idea de la escuela única, borrador de lo que pudiera haber sido una Ley General de Educación, que el país tanto necesitaba. Ya antes, en abril, había publicado también sus útiles Ideas para una reforma constitucional de la Educación Pública, un clásico hoy día en materia de política educativa curricular. Como se ve, el compromiso de Luzuriaga con la República era total.

Su carrera pedagógica se consolidará meses después, cuando inicie sus tareas como profesor de Organización escolar en la recién creada Sección de Pedagogía de la Universidad Complutense de Madrid y cuando sea nombrado Secretario Técnico en el Ministerio de Instrucción Pública y Bellas Artes, cargo que desempeñará hasta tiempo después de encontrarse ya en el exilio -1937, en Londres-.

En su obra La Nueva Escuela Pública (1931) desarrolla Luzuriaga su concepto de educación, su concepto de escuela y las características que debería tener la nueva escuela pública -tal y como indica el mismo título de la obra-. Aborda también el problema de los métodos de esta escuela y el de los procedimientos técnicos que le pueden servir.

En La escuela única, también de 1931, expone su idea de la unificación escolar, que desembocará un día en la célebre cuatrimembración de escuela única, activa, pública y laica. Es decir, única y no dividida, para todos y no para unos cuantos - renovación externa y problema principal de la educación contemporánea-; activa y no pasiva -metodológicamente renovada y renovadora-; pública y no privada, o sea, estatal, aunque lo privado queda para la experimentación pedagógica y la búsqueda de más calidad —que era a lo que se podía aspirar entonces-; y laica o no confesional, marcando el acento de la particular historia de la educación en España, es decir, la oposición entre pública-laica y privada-confesional.

Así pues, su compromiso político-profesional de 1931-1936 es la consecuencia de aquella toma de conciencia de la generación del 14 y también de los acontecimientos de 1917. El Luzuriaga socialista era el resultado, por ejemplo, de su trabajo en la Liga de Educación política (con Ortega y Azaña, a quienes tanto admiraba), pero sobre todo de su militancia en la Escuela Nueva de Núñez de Arenas, que tenía el mismo nombre del movimiento pedagógico internacional de renovación, pero que, sin embargo, nada tenía que ver con él desde el punto de vista organizativo o doctrinal. La Escuela de Núñez de Arenas era una institución típicamente socialista, en la que se buscaba la mejor síntesis y 
la más estrecha convivencia entre trabajadores manuales e intelectuales (las páginas de Tuñón de Lara son muy elocuentes al respecto...).

A partir de 1935 - año de la muerte de Cossío-, Castillejo y Luzuriaga, los dos pedagogos manchegos, quedarán como la referencia indiscutible de la honda y magna experiencia educativa que fue la Institución Libre de Enseñanza. Ellos son los herederos del viejo espíritu institucionista. Luzuriaga se halla muy próximo entonces a hombres como Américo Castro, Jiménez de Asúa y otros. Con todos ellos convivirá y mantendrá una estrecha relación. (Puede encontrarse una amplia información al respecto en mi artículo "Lorenzo Luzuriaga y el movimiento de la Escuela Única en España. De la renovación educativa al exilio (1913-1959)", publicado en la Revista de Educación, 289, 1989, Madrid, así como, para todo lo relacionado con la vida y obra de Lorenzo Luzuriaga en España, en mi libro Lorenzo Luzuriaga y la renovación educativa en España 1889-1936 (Ediciós do Castro), Sada-A Coruña, 1989, 355 págs).

El reconocimiento internacional de la obra pedagógica de Lorenzo Luzuriaga no llegaría hasta que inicia su etapa como publicista en la Editorial Losada y como profesor en la Universidad de Buenos Aires. Sus obras del exilio argentino son las que le dan popularidad en España a partir de los años 60. Por ellas empezará a ser conocido, aunque, en un primer momento, en círculos más bien restringidos y en ámbitos casi exclusivamente universitarios. A partir de los 70 y, sobre todo, de los 80 , su popularidad como teórico de la pedagogía o de la educación social, irá en aumento.

Además de las obras citadas al principio de estas notas biográficas, en los años argentinos publica Luzuriaga varias obras sobre la situación de la escuela primaria en Europa y en Hispanoamérica. Y aborda los nuevos grandes temas de la pedagogía contemporánea. Títulos suyos en Losada serán, por ejemplo, La educación nueva, La pedagogía contemporánea, Pedagogía social y política o La educación de nuestro tiempo. Como publicación póstuma y en homenaje, aparecerá en 1960 su Diccionario de Pedagogía.

Lorenzo Luzuriaga sólo volvería a España en una ocasión, en 1956. La impresión que recibe en aquel viaje es muy penosa. En algunas de sus cartas de los últimos años de su vida - moriría en Buenos Aires de una trombosis en 1959- se recoge su tristeza al comprobar a qué había quedado reducido, por ejemplo, el Museo Pedagógico Nacional o los propios locales de la ILE. Pero, sobre todo, se lamentaba amargamente del ambiente intelectualmente tan pobre que había encontrado. Efectivamente, una cosa es su obra en España — vital, plena, entusiasta - y otra, su trabajo en el exilio — pulcro, aseado..., melancólico—. En definitiva, un caso más entre los miles de la España peregrina...

(Publicado en J. A. Díaz (coord.), Castellanos sin mancha: exiliados castellano-manchegos tras la guerra civil, Madrid, Celeste, 1999, páxs. 31-42.) 